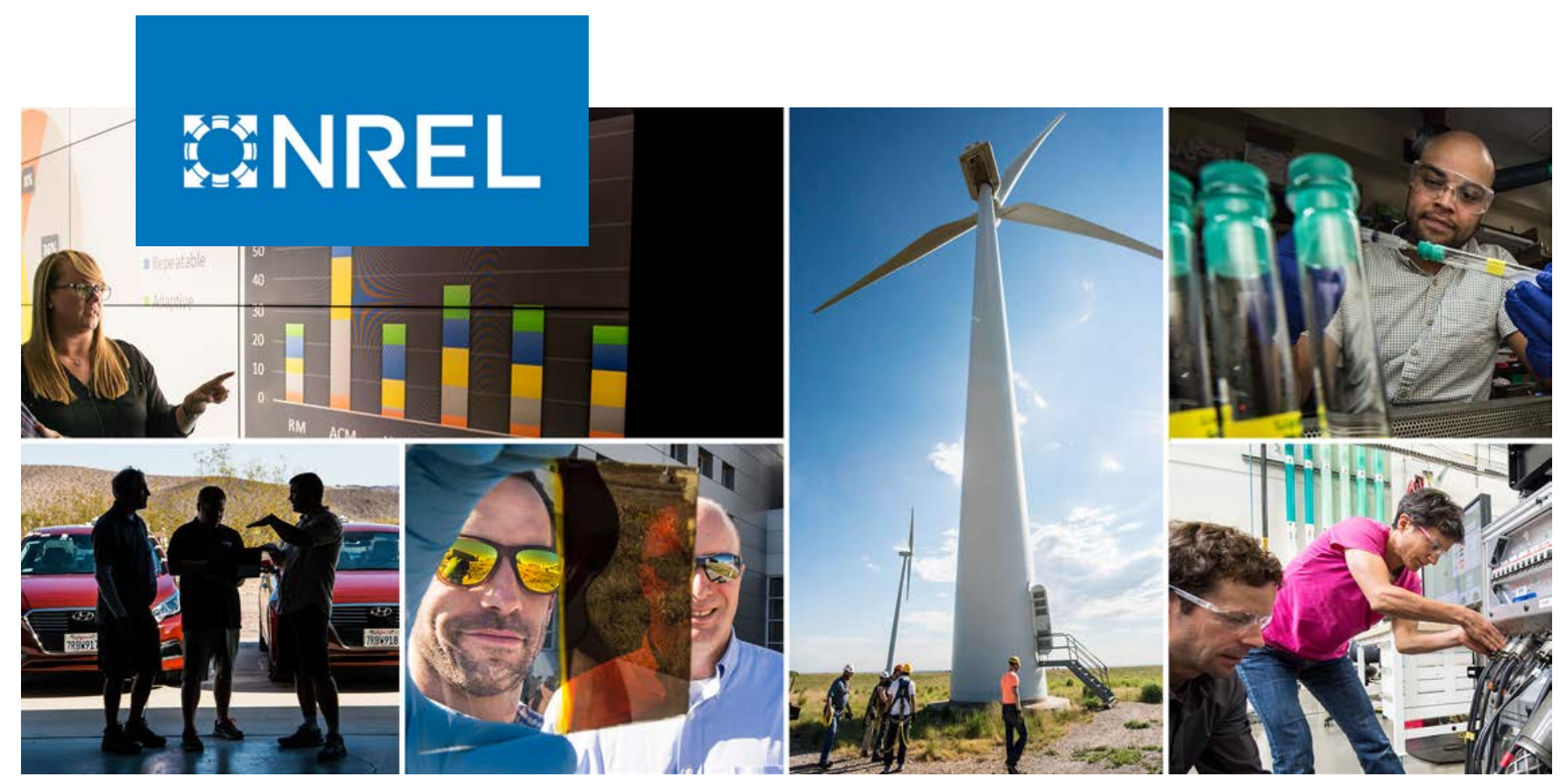

\title{
Inserting a Low-Refractive-Index Dielectric Rear Reflector into PERC Cells: Challenges and Opportunities
}

\section{Preprint}

Jonathan L. Bryan ${ }^{1}$, Lejo Joseph Koduvelikulathu ${ }^{2}$, Zih-Wei Peng ${ }^{2}$, Joe V. Carpenter III ${ }^{1}$, Michael G.

Deceglie $^{3}$, Timothy J. Silverman ${ }^{3}$, and Zachary C. Holman ${ }^{1}$

1 Arizona State University

2 International Solar Energy Research Center Konstanz e.V.

3 National Renewable Energy Laboratory

Presented at the 46th IEEE Photovoltaic Specialists Conference (PVSC 46)

Chicago, Illinois

June 16-21, 2019

NREL is a national laboratory of the U.S. Department of Energy

Office of Energy Efficiency \& Renewable Energy

Operated by the Alliance for Sustainable Energy, LLC

This report is available at no cost from the National Renewable Energy Laboratory (NREL) at www.nrel.gov/publications.
Conference Paper

NREL/CP-5K00-75157

December 2019 


\title{
WNREL
}

\section{Inserting a Low-Refractive-Index Dielectric Rear Reflector into PERC Cells: Challenges and Opportunities}

\section{Preprint}

\author{
Jonathan L. Bryan ${ }^{1}$, Lejo Joseph Koduvelikulathu², \\ Zih-Wei Peng ${ }^{2}$, Joe V. Carpenter III ${ }^{1}$, Michael G. \\ Deceglie $^{3}$, Timothy J. Silverman ${ }^{3}$, and Zachary C. Holman ${ }^{1}$
}

1 Arizona State University

2 International Solar Energy Research Center Konstanz e.V. 3 National Renewable Energy Laboratory

\section{Suggested Citation}

Bryan, Jonathan L., Lejo Joseph Koduvelikulathu, Zih-Wei Peng, Joe V. Carpenter III, Michael G. Deceglie, Timothy J. Silverman, Zachary C. Holman. 2019. Inserting a LowRefractive-Index Dielectric Rear Reflector into PERC Cells: Challenges and Opportunities: Preprint. Golden, CO: National Renewable Energy Laboratory. NREL/CP-5K00-75157. https://www.nrel.gov/docs/fy20osti/75157.pdf.

(c) 2019 IEEE. Personal use of this material is permitted. Permission from IEEE must be obtained for all other uses, in any current or future media, including reprinting/republishing this material for advertising or promotional purposes, creating new collective works, for resale or redistribution to servers or lists, or reuse of any copyrighted component of this work in other works.

NREL is a national laboratory of the U.S. Department of Energy Office of Energy Efficiency \& Renewable Energy Operated by the Alliance for Sustainable Energy, LLC

This report is available at no cost from the National Renewable Energy Laboratory (NREL) at www.nrel.gov/publications.

Contract No. DE-AC36-08GO28308
Conference Paper

NREL/CP-5K00-75157

December 2019

National Renewable Energy Laboratory 15013 Denver West Parkway Golden, CO 80401

303-275-3000 • www.nrel.gov 


\section{NOTICE}

This work was authored in part by the National Renewable Energy Laboratory, operated by Alliance for Sustainable Energy, LLC, for the U.S. Department of Energy (DOE) under Contract No. DE-AC36-08GO28308. Funding provided by U.S. Department of Energy Office of Energy Efficiency and Renewable Energy Solar Energy Technologies Office. The views expressed herein do not necessarily represent the views of the DOE or the U.S. Government. The U.S. Government retains and the publisher, by accepting the article for publication, acknowledges that the U.S. Government retains a nonexclusive, paid-up, irrevocable, worldwide license to publish or reproduce the published form of this work, or allow others to do so, for U.S. Government purposes.

This report is available at no cost from the National Renewable Energy Laboratory (NREL) at www.nrel.gov/publications.

U.S. Department of Energy (DOE) reports produced after 1991 and a growing number of pre-1991 documents are available free via www.OSTI.gov.

Cover Photos by Dennis Schroeder: (clockwise, left to right) NREL 51934, NREL 45897, NREL 42160, NREL 45891, NREL 48097, NREL 46526.

NREL prints on paper that contains recycled content. 


\title{
Inserting a Low-Refractive-Index Dielectric Rear Reflector into PERC Cells: Challenges and Opportunities
}

\author{
Jonathan L. Bryan ${ }^{1}$, Lejo Joseph Koduvelikulathu², Zih-Wei Peng ${ }^{2}$, Joe V. Carpenter III ${ }^{1}$, Michael G. \\ Deceglie $^{3}$, Timothy J. Silverman ${ }^{3}$, Zachary C. Holman ${ }^{1}$ \\ ${ }^{1}$ School of Electrical, Computer, and Energy Engineering, Arizona State University, Tempe, AZ, 85287, USA \\ ${ }^{2}$ International Solar Energy Research Center Konstanz e.V., 78467 Konstanz, Germany \\ ${ }^{3}$ National Center for Photovoltaics, National Renewable Energy Laboratory, Golden, CO, 80401, USA
}

\begin{abstract}
One of the simplest and most effective ways to reduce the operating temperature of photovoltaic systems in the field is to reflect unusable, "sub-bandgap" light with energies below the cell absorber's bandgap energy. In this work, lowrefractive index $\mathrm{SiO}_{2}$ nanoparticle films inserted between c-Si wafers and metal electrodes significantly increase the reflectance of sub-bandgap light in fabricated test structures. These films are then integrated into the standard PERC fabrication sequence, revealing that the reflection benefits remains after some processing steps but are lost in certain conditions. The $\mathrm{SiO}_{2}$ nanoparticle films are easily ablated during laser contact opening, but are undesirably etched during post-laser cleaning. After Al metallization, the fully fabricated devices show enhanced subbandgap reflection when annealed at moderate temperatures, but energy-dispersive $x$-ray spectroscopy shows that hightemperature firing causes unwanted Al penetration into the $\mathrm{SiO}_{2}$ nanoparticle film, compromising reflection.
\end{abstract}

Index Terms - crystalline silicon, optics, PERC solar cell, photovoltaic cells, photovoltaic systems, thermal management, energy yield, module temperature

\section{INTRODUCTION}

Reducing the operating temperature of photovoltaic (PV) modules in the field is an effective way to increase a PV system's lifetime [1] and energy yield [2]. One of the most promising methods to reduce module operating temperature is by rejecting incident radiation that is unusable by the device for electrical energy conversion; specifically, an ideal subbandgap reflector at the rear side of a solar cell is predicted to have up to a $3.8 \mathrm{~K}$ reduction in annual irradiance-weighted temperature in crystalline silicon solar cells [2]. Analysis by Vaillon et al. similarly found sub-bandgap reflectance to be a thermal management strategy worth pursuing [3]. Most parasitic absorption of sub-bandgap light occurs in the rear metal electrode in crystalline silicon (c-Si) solar cells, and a proven method to reduce it is to insert a low refractive index dielectric film between the c-Si substrate and metal [4-6]. These reflecting films are most effective when their thickness is over $200 \mathrm{~nm}$ and their refractive index is as low as possible - conditions that minimize the field strength of evanescent waves at the metal surface, thereby avoiding plasmonic absorption [7].

One method to achieve a target refractive index of a dielectric film is by controlling its porosity, the volumetric ratio of void to constituent material. This approach has been demonstrated using aerosol impaction-driven assembly (AIDA), a deposition technique that first aerosolizes constituent material before depositing it onto the substrate with an impaction velocity that may be controlled to tune porosity $[8,9]$. AIDA-deposited silicon nanoparticle (NP) films were previously tested by Boccard et al. as rear reflectors in silicon heterojunction (SHJ) cells and optical test structures [10]. These silicon NP films enabled reflectance of over $90 \%$ of sub-bandgap wavelengths when inserted between a c-Si wafer and $\mathrm{Ag}$ reflector, and were shown to improve rear reflectance in SHJ cells while simultaneously not degrading the fill factor or open-circuit voltage.

This work investigates silicon dioxide $\left(\mathrm{SiO}_{2}\right) \mathrm{NP}$ films for use as rear reflectors in c-Si solar cells. $\mathrm{SiO}_{2} \mathrm{NP}$ films offer considerable advantages over Si NP films: greater resilience when contacting $\mathrm{Al}$ at high temperatures and lower refractive index for equivalent film porosity. In Boccard's study, when the refractive index of the Si NP film was below 1.5, the measured reflectance at $1200 \mathrm{~nm}$ was well below the predicted simulation results (30\% absolute less reflectance for film with refractive index of 1.1). The discrepancy was attributed to the roughness of the NP film surface, which incited plasmonic absorption in the adjacent $\mathrm{Ag}$. Since the refractive index of dense $\mathrm{SiO}_{2}$ is lower than that of $\mathrm{Si}$, it is easier to attain minimum refractive indices, which lead to maximum reflectance in devices, without resorting to extreme porosities that compromise smooth interfaces. These films are incorporated into a standard PERC - as opposed to the lesscommon SHJ-fabrication sequence, testing compatibility with subsequent solar cell processing.

\section{EXPERIMENTAL METHODS}

Low-refractive-index $\mathrm{SiO}_{2} \mathrm{NP}$ films were tested in optical test structures and within a standard PERC processing sequence. The $\mathrm{SiO}_{2} \mathrm{NP}$ films were deposited using the AIDA process previously mentioned [8]. The $\mathrm{SiO}_{2}$ NPs were synthesized upstream of the deposition nozzle in a dusty plasma using silicon- and oxygen-containing precursors. A pressure gradient between the upstream synthesis chamber and low-pressure deposition chamber accelerates the $\mathrm{SiO}_{2} \mathrm{NPs}$ 
through the slit-shaped nozzle, where they impact and adhere to the substrate. In the downstream deposition chamber, the substrate is translated beneath the nozzle to control deposition area, porosity, film thickness, and achieve a good uniformity. The stoichiometry and average primary particle size of the $\mathrm{SiO}_{2}$ films is controlled with precursor gas flow rates and chamber pressure of the plasma reactor. In this work, the $\mathrm{SiO}_{2}$ films were stoichiometric with average particle size approximately $5 \mathrm{~nm}$, confirmed with energy-dispersive X-ray spectroscopy (EDXS) and transmission electron microscopy, respectively. The film thickness, porosity, and surface roughness were measured with a JA Woollam M2000 spectroscopic ellipsometer. A Bruggeman effective-medium approximation was used with $\mathrm{SiO}_{2}$ and void as the model inputs. This characterization was similarly performed, and its accuracy verified, in previous work on other materials This characterization was similarly performed, and its accuracy verified, in previous work on other materials $[8,10]$.

Before implementing the NP films in devices, optical test structures were made to demonstrate the reflectance benefits and expected optical performance limit of the final cells. Monocrystalline silicon substrates were double-side textured using standard $\mathrm{KOH}$ etching and cleaned with Piranha, RCA$\mathrm{B}$, and $\mathrm{BOE}$ before subsequent depositions. The front side of all samples was coated with an 80 -nm-thick $\mathrm{SiN}_{\mathrm{x}}$ antireflection coating, deposited with plasma-enhanced chemical vapor deposition. Several material stacks were tested on the rear side: NPs/Al, NPs/Ag, ITO/Ag, and Ag or Al references with no NPs, with the $\mathrm{Al}, \mathrm{Ag}$, and ITO layers sputtered in all cases. The target $\mathrm{SiO}_{2} \mathrm{NP}$ film properties were a refractive index of 1.4 and thickness of $275 \mathrm{~nm}$. Somewhat high refractive index was used (1.4 instead of 1.1-1.2, which is achievable with AIDA) to ensure minimal surface roughness. Planar c-Si witness samples analyzed with ellipsometry confirmed the consistency of film properties from run to run.

To test their compatibility in PERC processing, $\mathrm{SiO}_{2} \mathrm{NPs}$ were deposited on the rear-side of PERC-like precursors fabricated at ISC Konstanz, as seen in Figure 1. The precursors consisted of p-type c-Si wafers with a phosphorusdiffused front surface and a standard $\mathrm{SiO}_{2} / \mathrm{SiN}_{\mathrm{x}}$ passivation stack on the rear side. The same $\mathrm{SiO}_{2} \mathrm{NP}$ film properties used in the optical test structures were targeted here: refractive index of 1.4, thickness of $275 \mathrm{~nm}$, and minimal roughness ( $2 \mathrm{~nm}$ measured with ellipsometry). $\mathrm{SiO}_{2} \mathrm{NP}$ films were deposited on eight 6" PERC precursor samples and two 5" front-side-polished c-Si substrates for process compatibility tests. Specifically, the tested process steps were laser contact opening, post-laser wet chemistry cleaning, and $\mathrm{Al}$ metallization. A Rolfin StarFemto FX laser was used to ablate the $\mathrm{SiO}_{2} \mathrm{NP}$ film and passivation stack for the laser contact opening. After contact opening, a 60 second dip in $2 \%$ $\mathrm{HF} / \mathrm{HCl}$ was performed for cleaning. Full-area $\mathrm{Al}$ metallization was then deposited on the back side using three different techniques: screen print and high-temperature firing in belt furnace $\left(850{ }^{\circ} \mathrm{C}\right.$ peak temperature), screen print and low-temperature drying $\left(200{ }^{\circ} \mathrm{C}\right.$ for 20 minutes $)$, and sputtering. The reflectance of the fully fabricated cells and optical test structures was measured using a PerkinElmer Lambda 950 spectrophotometer. Select samples were cleaved and their cross-sections imaged with scanning electron microscopy (SEM) and EDXS, performed with a ZEISS Auriga microscope.

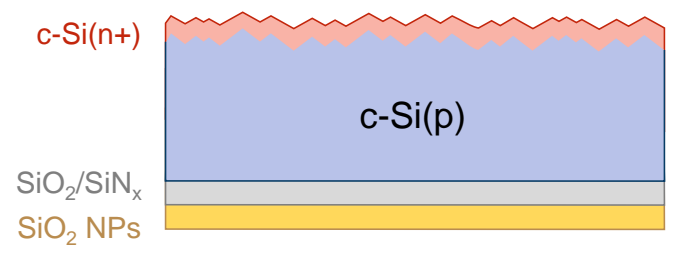
- Laser contact opening
- Post-laser HF/HCl clean
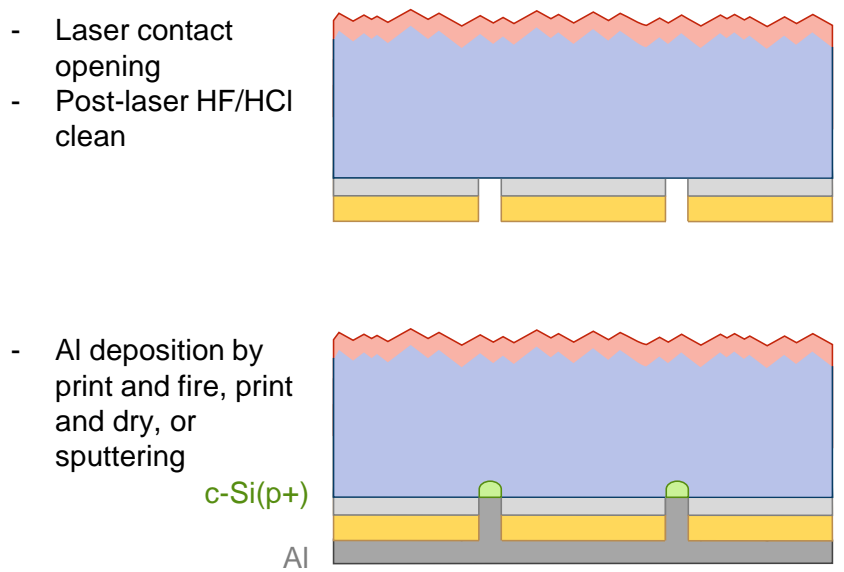

Fig. 1. Schematic of the PERC cell fabrication steps.

\section{RESULTS}

\section{A. Optical Test Structures}

Figure 2 shows a schematic of the fabricated optical test structures and the reflectance of each sample. The results show that for both $\mathrm{Al}$ and $\mathrm{Ag}$, reflectance values are significantly higher with the inclusion of the $\mathrm{SiO}_{2} \mathrm{NP}$ film, and both structures outperform the ITO/Ag reference. At $1200 \mathrm{~nm}$, the reflectance of the Al-metallized test structures increased from 19.3 to $72.8 \%$ when the $\mathrm{SiO}_{2}$ NP reflector is included. Since these test structures are double-side textured, and do not have heavily doped emitters or passivation stacks, this observed boost in reflectance is higher than expected when integrating the $\mathrm{SiO}_{2} \mathrm{NP}$ film in typical solar cell structures. Nonetheless, inclusion of these films within the optical test structures demonstrates promise to considerably reduce parasitic absorption in the rear metallized area in solar cells. Successful integration of these structures in solar cells is expected reduce operating temperature of PV modules in the field [2]. 
(a)

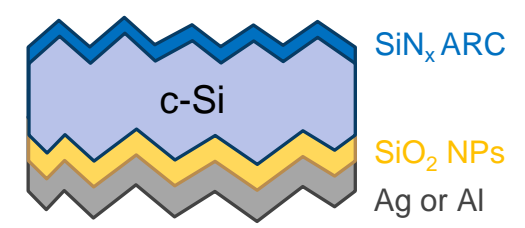

(b)

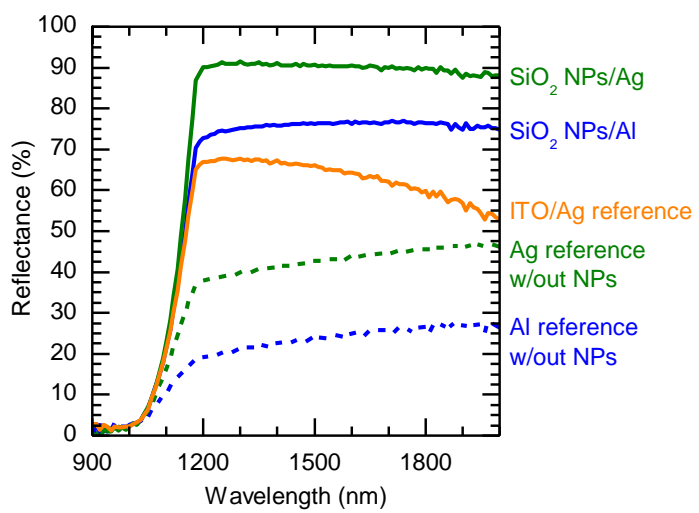

Fig. 2. (a) Schematic of the test structures used to measure reflectance and (b) the reflectance data of the test structures.

\section{B. Laser Opening}

Figure 3a shows the contact opening of the passivation stack without the $\mathrm{SiO}_{2} \mathrm{NP}$ reflector using ISC Konstanz's standard laser process with a fluence of $13.8 \mathrm{~mJ} / \mathrm{cm}^{2}$. As expected, a clean, fully opened point exposes the underlying c-Si wafer, which appears blue in the optical micrographs. This same laser recipe was used on the structure with a $\mathrm{SiO}_{2} \mathrm{NP}$ film, shown in Figure $3 b$. It is evident that this laser process had insufficient
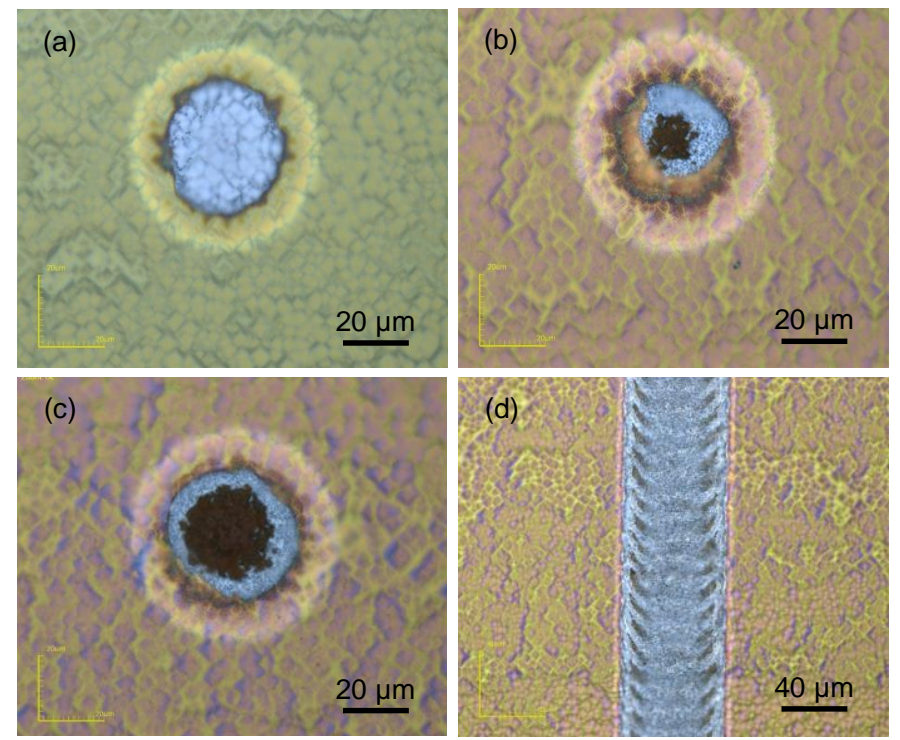

Fig. 3. Optical microscope images after laser ablation for (a) standard PERC passivation stack without $\mathrm{SiO}_{2} \mathrm{NP}$ film at baseline laser fluence, (b) PERC passivation stack with $\mathrm{SiO}_{2} \mathrm{NP}$ film at baseline laser fluence, (c) PERC passivation stack with $\mathrm{SiO}_{2} \mathrm{NP}$ film at higher laser fluence, and (d) PERC passivation stack with $\mathrm{SiO}_{2} \mathrm{NP}$ film at higher laser fluence and with linear translation showing good contact opening. power to create an opening to the c-Si substrate. Instead, it appears the $\mathrm{SiO}_{2} \mathrm{NP}$ film absorbed the laser energy and melted, forming the dark brown region in the center of the ablated area, which would impede contact formation. Increasing the laser fluence from 13.8 to $18.5 \mathrm{~mJ} / \mathrm{cm}^{2}$ appears to exacerbate this issue for the point ablation, as seen in Figure 3c. However, for linear contact openings, the translated laser can evaporate the $\mathrm{SiO}_{2}$ residue, resolving the problem; Figure $3 \mathrm{~d}$ shows a clear linear opening to the $\mathrm{c}-\mathrm{Si}$ wafer with the increased laser power $\left(18.5 \mathrm{~mJ} / \mathrm{cm}^{2}\right)$.

\section{Post-Laser Cleaning}

The planar samples with $\mathrm{SiO}_{2} \mathrm{NP}$ films were dipped for various times in an $\mathrm{HF} / \mathrm{HCl}$ cleaning solution designed to remove passivation film residue formed in the laser process he planar samples containing $\mathrm{SiO}_{2} \mathrm{NP}$ films were dipped in the $\mathrm{HF} / \mathrm{HCl}$ laser cleaning solution for various times. After each dip, the $\mathrm{SiO}_{2}$ NP films were measured with ellipsometry. Figure 4 shows the average film thickness after the cleaning times and reveals that the NP films were rapidly etched in the cleaning solution. This is substantiated by photos of the samples, which underwent drastic color changes as the interference condition shifted with the optical thickness of the film, as also seen in Figure 4. This result represents a challenge, as significant reduction in $\mathrm{SiO}_{2} \mathrm{NP}$ film thickness will reduce its efficacy as a rear reflector. Further studies investigating the etch rate of films composed of NPs of other (low-refractive-index) materials, such as $\mathrm{MgF}_{2}$, could reveal pathways to mitigate or eliminate film loss. Since the etch rate was extremely fast, the post-laser cleaning step was skipped for samples before $\mathrm{Al}$ metallization.

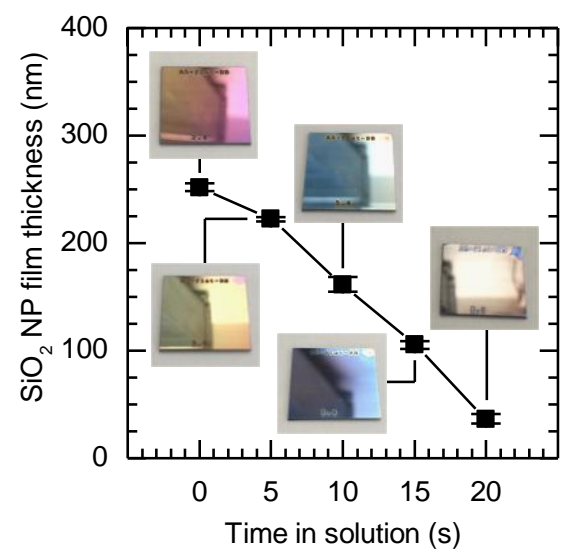

Fig. 4. $\mathrm{SiO}_{2} \mathrm{NP}$ film thickness after dipping in $\mathrm{HF} / \mathrm{HCl}$ post-laser cleaning solution.

\section{Al Metallization}

As previously described, three Al metallization methods were tested to compare their performance. Figure 5 shows the reflectance of the PERC precursor samples after each metallization sequence, with and without the $\mathrm{SiO}_{2} \mathrm{NP}$ film. 


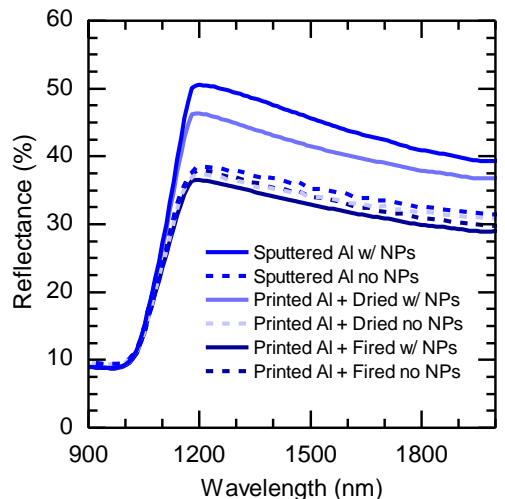

Fig. 5. Reflectance data of the fully fabricated PERC structures with and without $\mathrm{SiO}_{2} \mathrm{NPs}$.

The data reveals that sputtered $\mathrm{Al}$ exhibits a greater reflectance boost compared to both screen-printed Al structures. The reflectance at $1200 \mathrm{~nm}$ for the sputtered, dried, and fired samples with $\mathrm{SiO}_{2} \mathrm{NPs}$ is 50.5, 46.4, and 36.5\%, respectively. The reason the sputtered $\mathrm{Al}$ sample does not reach the $72.8 \%$ reflectance seen in the test structure is that the PERC precursor, with its planar rear side and heavily doped layers, has infrared parasitic absorption occurring in regions besides the rear reflector. The optical role of the $\mathrm{SiO}_{2} / \mathrm{SiN}_{\mathrm{x}}$ passivation stack can be seen in the sputtered $\mathrm{Al}$ sample without NPs; at $1200 \mathrm{~nm}$, the reflectance in the cell was 1200 $\mathrm{nm}$, while the $\mathrm{Al}$ test structure reference was $19.3 \%$. This optical difference between PERC and Al-BSF, a consequence of the properties of the passivation stack, was found to appreciably reduce operating temperature in simulation and indoor testing [11]. The most striking aspect of the reflectance data is the observed reduction in reflectance for the cell that underwent high-temperature firing after $\mathrm{Al}$ screen-printing.

Figure 6, which is an SEM image and compositional map from the fired sample, shows clear evidence that $\mathrm{Al}$ from the paste micro-particles has penetrated into the $\mathrm{SiO}_{2} \mathrm{NP}$ film. This Al diffusion likely affects the optical properties of the

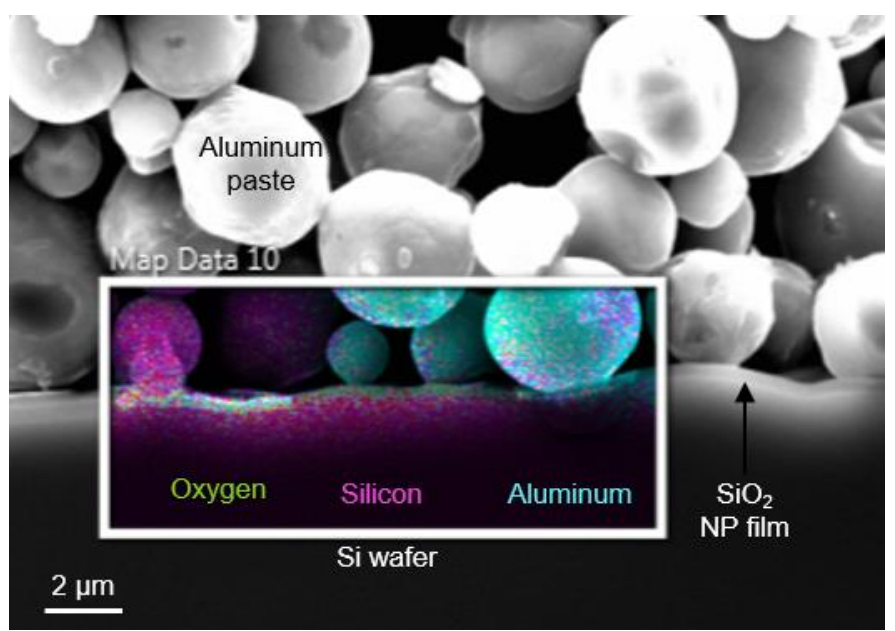

Fig. 6. SEM image with EDXS of PERC structure with $\mathrm{SiO}_{2} \mathrm{NP}$ film after $\mathrm{Al}$ screen printing and high-temperature firing. reflector layer, explaining the observed decrease in reflectance. Since the (low-temperature) dried samples did not suffer from this reflectance degradation, further studies of processing compatibilities at intermediate firing temperature ranges should be performed.

\section{CONCLUSIONS}

$\mathrm{SiO}_{2} \mathrm{NP}$ films, when incorporated on the rear side of $\mathrm{c}-\mathrm{Si}$ PV cells, significantly increase sub-bandgap reflectance. This study represents the initial findings for adopting such films into PERC processing technology to enhance thermal management in fielded modules. While some processes showed no or benign effects from the addition of the NP film, the post-laser etching and high-temperature firing steps were particularly detrimental to its stability. A logical next step is further studies on the relationship between film properties, such as stoichiometry and pore size, and chemical stability during these processes. Since the reflectors can considerably reduce parasitic absorption and thus module operating temperature, overcoming these remaining processing challenges can lead to higher PV system energy yield.

\section{ACKNOWLEDGEMENTS}

This work was authored in part by Alliance for Sustainable Energy, LLC, the manager and operator of the National Renewable Energy Laboratory for the U.S. Department of Energy (DOE) under Contract No. DE-AC36-08GO28308. Funding provided by the U.S. Department of Energy's Office of Energy Efficiency and Renewable Energy (EERE) under Solar Energy Technologies Office (SETO) Agreement Number 30312. The views expressed in the article do not necessarily represent the views of the DOE or the U.S. Government. The U.S. Government retains and the publisher, by accepting the article for publication, acknowledges that the U.S. Government retains a nonexclusive, paid-up, irrevocable, worldwide license to publish or reproduce the published form of this work, or allow others to do so, for U.S. Government purposes.

This material is based upon work primarily supported by the Engineering Research Center Program of the National Science Foundation and the Office of Energy Efficiency and Renewable Energy of the Department of Energy under NSF Cooperative Agreement No. EEC-1041895. We acknowledge the use of facilities within the Eyring Materials Center at Arizona State University.

\section{REFERENCES}

[1] S. Kurtz, K. Whitfield, G. TamizhMani, M. Koehl, D. Miller, J. Joyce, J. Wohlgemuth, N. Bosco, M. Kempe, and T. Zgonena, "Evaluation of high-temperature exposure of photovoltaic modules," Prog. Photovolt., Res. Appl., vol. 19, no. 8, pp. 954965, 2011.

[2] T. J. Silverman, M. G. Deceglie, I. Subedi, N. J. Podraza, I. M. Slauch, V. E. Ferry, and I. Repins, "Reducing Operating 
Temperature in Photovoltaic Modules," IEEE J. of Photovoltaics 8, 532, 2018.

[3] R. Vaillon, O. Dupré, R. B. Cal, and M. Calaf, "Pathways for mitigating thermal losses in solar photovoltaics," Sci. Rep., vol. 8, no. 1, Art. no. 13163, 2018.

[4] Z. C. Holman, M. Filipič, A. Descoeudres, S. De Wolf, F. Smole, M. Topič, and C. Ballif, "Infrared light management in high-efficiency silicon heterojunction and rear-passivated solar cells," J. Appl. Phys., vol. 113, p. 013107, 2013.

[5] Z. C. Holman, A. Descoeudres, S. De Wolf, and C. Ballif, "Record Infrared Internal Quantum Efficiency in Silicon Heterojunction Solar Cells with Dielectric/Metal Rear Reflectors," IEEE J. Photovoltaics, vol. 3, pp. 1243-1249, 2013.

[6] Z. C. Holman, M. Filipič, B. Lipovšek, S. De Wolf, F. Smole, M. Topič, and C. Ballif, "Parasitic absorption in the rear reflectors of silicon solar cells: Simulation and measurement of the sub-bandgap reflectance for common dielectric/metal reflectors," Solar Energy Mater. Solar Cells, vol. 120, pp. 426430, 2014.

[7] Z. C. Holman, S. De Wolf, and C. Ballif., "Improving metal reflectors by suppressing surface plasmon polaritons: A priori calculation of the internal reflectance of a solar cell," Light: Sci. Appl. vol 2, p. e106, 2013.

[8] P. Firth and Z. C. Holman, "Aerosol Impaction-Driven Assembly System for the Production of Uniform Nanoparticle Thin Films with Independently Tunable Thickness and Porosity", ACS Appl. Nano Mater., vol. 1, no. 8, pp. 43514357, 2018.

[9] Z. C. Holman and U. Kortshagen, "A flexible method for depositing dense nanocrystal thin films: Impaction of germanium nanocrystals," Nanotechnology, vol. 21, p. 335302, 2010.

[10] M. Boccard, P. Firth, Z. J. Yu, K. C. Fisher, M. Lailaeioun, S. Manzoor, and Z.C. Holman, "Low-refractive index nanoparticle interlayers to reduce parasitic absorption in metallic rear reflectors of solar cells," Physica Status Solidi, vol. 214, issue 10, 2017.

[11] M. R. Vogt, H. Schulte-Huzel, M. Offer, S. Blankemeyer, R. Witteck, M. Köntges, K. Bothe, and R. Brendel "Reduced module operating temperature and increased yield of modules with PERC instead of Al-BSF solar cells," IEEE J. Photovolt., vol. 7, no. 1, pp. 44-50, Jan. 2017. 